\title{
Da burocracia à ad hocracia
}

\author{
Flavio A. de Andrade Goulart \\ Rosani Evangelista da Cunha
}

\section{Introdução}

É fato notório que a discussão sobre a estrutura organizacional dos órgãos de saúde está se tornando uma preocupação cada vez mais usual entre os vários interessados na questão. Na verdade, o problema da gestão na saúde e em outras áreas sociais pode ser apontado como reflexo das profundas variações nos contextos histórico, político, econômico e social vividos pelos diferentes países, nesse final de século. Nesse sentido, as discussões, acerca do tema, não são exclusivas do nosso País, mas refletem, entre outras coisas, a busca de competitividade dos diferentes países na nova ordem mundial e a necessidade de as organizações adaptarem-se a um cenário de incertezas, em termos políticos, demográficos, epidemiológicos etc.

Esse pequeno ensaio procurará demonstrar a pertinácia das contribuições do autor canadense, Henry Mintzberg, no entendimento do que ele próprio denomina como estrutura e dinâmica das organizações, aplicadas às organizações públicas de saúde. Mintzberg, na verdade, escreve tendo em vista as complexas organizações empresariais e mesmo estatais do Primeiro Mundo. Contudo, como se verá, suas idéias são ainda pertinentes, mesmo com relação a uma realidade diferente da original, como é o caso brasileiro (Mintzberg, 1995).

Inicialmente, seria útil localizar H. Mintzberg no âmbito das escolas de pensamento em administração correntes.

São quatro as perspectivas de análise das escolas de administração, a saber: a) a perspectiva racional, que baseada na contribuição da administração científica também é conhecida como escola taylorista;

Flavio A. de Andrade Goulart, docente da Faculdade de Ciências da Saúde/UnB e doutorando em Saúde Pública na ENSP/ FIOCRUZ, Rio de Janeiro. Rosani

Evangelista da Cunha, mestranda em Administração na FACE/UFMG e assessora técnica da Frente Nacional de Prefeitos 
b) a perspectiva natural, que incorpora a contribuição da escola de relações humanas e comportamentais e a teoria sistêmica/contingencial; c) a perspectiva política, que trabalha com a comparação da organização a um sistema político; d) a perspectiva múltipla, que se caracteriza por reconhecer a necessidade de utilizar diferentes formas de ver e explicar a organização, uma vez que os problemas organizacionais apresentam-se de forma contraditória, exigindo que se lance mão de diferentes ângulos de percepção e intervenção (Lemos \& Barbosa, 1998).

Cada uma das perspectivas relatadas põe em destaque um determinado fator condicionante, a partir do qual se explica a forma de adequação do funcionamento da organização. São considerados como fatores condicionantes de uma organização: a) as pessoas; b) a estrutura, com a correspondente divisão do trabalho e hierarquia; c) a tecnologia, compreendida como o processo de trabalho; d) os objetivos ou estados futuros desejados; e) o poder ou capacidade de influenciar; f) o ambiente, fonte de insumos e receptor dos produtos organizacionais.

A perspectiva múltipla, à qual pertence o autor em pauta, leva em consideração esse conjunto de fatores e tem como pressuposto que os sistemas de direção, mais adequados para as organizações de saúde, precisam lidar com múltiplas dimensões. Além do mais, aceita que a realidade organizacional é melhor apreendida mediante a confrontação das distintas explicações possíveis. As organizações são, portanto, simultaneamente, sistemas técnicos, racionais, funcionais e políticos.

\section{As organizações de saúde como organizações complexas}

A discussão sobre a estrutura organizacional para a gestão é decorrente da organização de uma nova ordem do trabalho e de modificações substanciais no uso da tecnologia, o que define bases significativamente diferentes para o funcionamento das organizações, particularmente quando seu objeto é a saúde.

Ao mesmo tempo, e em especial nos países da América Latina, dentre eles o Brasil, duas outras razões juntam-se às anteriores e potencializam as demandas por um novo papel a ser desempenhado pelas organizações de saúde, especialmente na área pública. A primeira dessas razões está no contexto de crise e de reformas nas funções desempenhadas pelo Poder Público; a segunda, nos processos de descentralização e de democratização em curso. O contexto de crise e a concomitante escassez de recursos têm acirrado a demanda por uma administração eficiente. Esse processo tem sido acompanhado pelo aumento e por uma maior complexidade das políticas públicas, com decorrentes demandas por novos 
padrões de eficiência e novas formas de relacionamento dos dirigentes e dos gestores públicos com a sociedade.

O processo de democratização, em curso no Brasil, tem levado a um fortalecimento da sociedade civil, e a um aumento da cobrança por melhores resultados do Estado e de suas organizações. Ou seja, a sociedade passa a exercer significativas pressões no sentido de uma maior competência do Estado em suas funções de formulação de políticas, coordenação, regulação e prestação de serviços.

A descentralização de políticas públicas, como acontece no Sistema Único de Saúde/SUS, ao transferir para níveis mais periféricos as decisões e as ações antes centralizadas, também contribui para a construção de um novo papel para as organizações e seus gestores. Ao lado da democratização, a descentralização de funções e de responsabilidades possibilita à sociedade novos instrumentos de cobrança e fiscalização da execução de políticas e torna possível a exigência de respostas efetivas às demandas.

No setor saúde, esse conjunto de transformações destaca-se, principalmente no nível municipal, que passa a assumir atribuições inovadoras para as quais muitos organismos de gestão ainda não acumulam experiência. Além disso, o acréscimo em termos de execução, controle e regulação de mercado obriga a utilização de novos instrumentos gerenciais, ajustados ao contexto da gestão pública.

A implementação e a operacionalização do SUS, de acordo com os princípios definidos pela Constituição Federal e pelas leis que as regulamentam, definem novas exigências para o Poder Público que resultam na necessidade de estruturas organizacionais coerentes com as transformações das práticas no setor.

Além do mais, as organizações de saúde, mesmo as pequenas, são sempre organizações complexas. Quais seriam os atributos determinantes dessa categoria? Poder-se-iam enumerá-los de forma sintética: as características profissionais de tais organizações, sua atuação na área de saúde e sua natureza pública (Dussault, 1992).

O conceito de organização profissional é intensivamente discutido por Mintzberg. Organização profissional é aquela cujo funcionamento depende, basicamente, de seus operadores, em que o trabalho desenvolvido é pouco formalizado e demanda um alto nível de qualificação. Outras organizações possuem essas mesmas características, como as escolas, as firmas de engenharia, de serviços jurídicos, dentre outras. O trabalho desenvolvido nessas organizações depende de um alto nível de qualificação e de uma complexa padronização. Assim, em função da complexidade e da variabilidade do trabalho desenvolvido, os profissionais que atuam nessa área mantêm uma certa autonomia na conduta de sua prática cotidiana, dificultando o trabalho dos gerentes e a incorporação dos objetivos organizacionais. 
O atributo da autonomia é central na caracterização de uma organização profissional. A regulação do trabalho desse tipo de profissional quase sempre é feita pela própria corporação, ou seja, pelos seus pares, por meio de entidades de fiscalização do exercício profissional, como os conselhos profissionais, portanto com controle e normatização exercidos de fora dos domínios da organização. Mintzberg descreve a força organizacional oriunda destes quadros como proficiência, um fator profundamente importante na configuração institucional. Um dos grandes problemas da gestão nas organizações profissionais é, justamente, a difícil conciliação entre a autonomia profissional e a necessidade de que os profissionais incorporem os objetivos da organização. Caso haja um controle exagerado, pode-se dificultar o trabalho desses profissionais; ao mesmo tempo, se não existe uma coordenação eficaz por parte do dirigente e da própria equipe, a organização pode correr o risco de uma desintegração institucional e da desarticulação do trabalho ali desenvolvido. As organizações profissionais atuam em um ambiente geralmente complexo, embora estável. A autonomia profissional e a dificuldade de controle desse tipo de trabalho fazem com que muita centralização e burocratização sejam mecanismos incompatíveis com a produção de serviços de boa qualidade.

O segundo atributo considerado para definir as organizações de saúde como organizações complexas é justamente o fato de trabalharem com saúde, o que define características próprias de organização e gestão. O próprio conceito do que seja saúde é variável e incorpora dimensões bastante ampliadas, basta ver a definição constitucional de saúde como "direito de todos e dever do Estado, a ser assegurado mediante políticas econômicas e sociais...". Ao mesmo tempo, o conceito e as percepções de saúde dos indivíduos e da coletividade incorporam aspectos éticos, morais, sociais, econômicos, religiosos e outros bastante diversificados. Os profissionais de saúde atuam em campos repletos de valores éticos e morais como: a influência sobre a vida e a morte, a relação entre sigilo profissional e direito à informação, escolha entre prioridades num contexto de escassez e outros igualmente complexos.

Tudo isso faz com que o trabalho na área de saúde seja realmente muito complexo, que demande alta qualidade, mas não possa ser muito formalizado, uma vez que os profissionais precisam considerar seus próprios valores e se adaptar às expectativas e às necessidades dos usuários. Novamente, retorna o conceito de autonomia anteriormente definido. Além disso, a área de saúde é uma arena de disputa entre vários atores sociais com interesses próprios, nem sempre convergentes, dentre eles os usuários, os trabalhadores, as corporações, os empresários e os políticos. Tais interesses expressam o papel social desempenhado pelo indivíduo ou segmento em cada momento e as concepções anteriormente explicitadas. Outra característica das organizações de saúde, que 
também contribui para sua complexidade, é a dificuldade em avaliar e em mensurar os resultados dos serviços prestados.

O terceiro atributo é o caráter público das ações e dos serviços de saúde desenvolvidos pelo aparelho do Estado, o que também, pelas características próprias das organizações públicas, pressupõe especificidade e complexidade para as mesmas. Esse tipo de organização é dependente do poder político e é regulado de maneira externa, com determinantes que se encontram fora do seu controle específico. Três questões principais devem ser consideradas para o entendimento das organizações públicas: a autoridade do dirigente é delegada; existe uma dependência de recursos públicos; e, por fim, as organizações públicas têm obrigação de prestar serviços.

Cabe discutir um pouco mais a primeira questão considerada, a autoridade delegada. $\mathrm{O}$ que significa isso? A autoridade dos dirigentes das organizações públicas é delegada pelos governantes e, no caso de órgãos com previsão de eleição para escolha de cargos de chefia, é dependente também daqueles profissionais ou usuários com poder de voto. Assim, o desempenho das funções de direção deve considerar os interesses de todos esses segmentos e, ao mesmo tempo, deve se pautar pelos objetivos governamentais. No caso do setor saúde, a Constituição Federal incorpora ainda o princípio da democratização da gestão, ou seja, da participação da sociedade na definição de estratégias e diretrizes de ação, no acompanhamento, no controle e na avaliação das ações e de serviços desenvolvidos. Muitas vezes, os interesses dos governantes, dos trabalhadores e da população são contraditórios, com preocupações políticas, sociais ou mesmo burocráticas que têm pouco a ver com as finalidades dos serviços de saúde. Isso significa que o dirigente de organizações públicas de saúde pode encontrar muitas dificuldades para considerar na sua ação os objetivos dos governantes, da população e dos trabalhadores. Ou seja, ele deve ter uma grande capacidade de negociação e legitimação junto a todos esses segmentos.

Além de ter a sua autoridade delegada e, conseqüentemente, ter de prestar contas de suas atividades, a autonomia dos dirigentes de saúde também é afetada pelo fato de atuarem em organizações financiadas por recursos públicos, geralmente escassos e negociados com outras áreas de governo e com outras políticas públicas que também disputam os mesmos recursos. Esse problema é agravado nos contextos de crise e escassez e depende das prioridades dos governantes e da capacidade de arrecadação do Estado. Assim, por mais que a saúde seja uma ação importante, a sua dependência de recursos públicos faz com que participe de disputas com outros segmentos pelos mesmos recursos públicos que financiam ações tão importantes quanto ela. Ao mesmo tempo, o Estado tem obrigação de garantir o direito à saúde de todos os cidadãos, como determina a 
Constituição Federal, e isto significa que, ao contrário dos serviços privados, os serviços públicos têm um dever de atendimento.

\section{As funções de gestão em saúde}

As funções gerenciais no SUS podem ser discutidas a partir de duas dimensões distintas, uma mais estratégica e mais política e outra técnica, sanitária e administrativa. No primeiro grupo, também chamado de atividades de gestão, estão as atividades de coordenação, regulação, negociação e condução estratégica do sistema de saúde. Essas atividades correspondem às instâncias de comando do SUS, nos seus níveis municipal, estadual e nacional (Müller, 1993).

Em relação ao segundo grupo, ou atividades de gerência (ou também gestão de serviços), temos uma atuação voltada para a administração de órgãos ou instituições que se caracterizam como prestadores de serviços ao sistema, sejam eles ambulatório, hospital, instituto, fundação ou outros. É claro que essas não são atividades excludentes, e os gerentes de serviços, por exemplo, têm de exercitar a coordenação, a negociação e a gestão estratégica no seu âmbito de atuação, conforme está explicitado na Norma Operacional Básica/NOB do SUS de 1996.

Ao conjunto de atributos de gestão e de gerência, relacionados ao âmbito dos sistemas e serviços de saúde, seja no plano político, técnicofinalístico ou técnico-administrativo, denomina-se funções de gestão.

As funções de gestão em saúde derivam diretamente das diretrizes estabelecidas na Constituição Federal de 1988, particularmente o dever do Estado (art. 196), a relevância pública (art. 197) e a direção única em cada esfera de governo (art. 198).

Além dessas, a integração das políticas sociais (art. 196), a participação da sociedade e a nova organização regionalizada e hierarquizada do sistema (art. 198), bem como as competências específicas definidas no artigo 200 da Constituição vêm a exigir um perfil organizacional bastante diferente daquele que tem vigorado ao longo de toda a história do sistema, marcada pela fragmentação e pela descoordenação das ações.

O SUS, ancorado nos princípios mencionados, requer, sem dúvida, novas maneiras de praticar a gestão, advindo, daí, grandes desafios ao corpo de dirigentes e técnicos envolvidos no processo gerencial.

Uma série de conseqüências deriva diretamente dos princípios jurídicos do SUS. Os gestores do sistema e os gerentes dos serviços devem estar atentos às mesmas, pelas suas implicações no cotidiano do processo administrativo. O quadro a seguir resume alguns aspectos das novas responsabilidades de gestão despertadas pela implantação do novo sistema de saúde. 
Quadro 1: As responsabiliades de gestão no novo modelo do sistema público de saúde

Intersetorialidade: a ação gerencial, freqüentemente, ultrapassa os limites do setor saúde, seja em direção a outras instituições, estatais e não-estatais, ou a entidades vinculadas à sociedade civil.

Responsabilidade sobre a coisa pública, incluindo o uso dos recursos públicos na contratação de serviços privados complementares.

Universalidade e integralidade, responsabilidade pela saúde do conjunto dos cidadãos e nas diversas condições de vida e situações de risco.

Defesa dos interesses coletivos, implícitos no direito à saúde, particularmente na garantia da universalidade, da integralidade e da eqüidade.

Relevância pública: o Estado tem responsabilidade pelo conjunto de ações e serviços de saúde, independentemente da execução direta dos mesmos.

Domínio de meios e fins, técnicos, políticos e comunicativos, visando à promoção do direito universalizado à saúde.

Gestão intergovernamental: decorrente da responsabilidade das três esferas de governo com a saúde e da necessidade de garantia da unicidade do sistema de saúde.

Controle social, com submissão à ação deliberativa e fiscalizadora dos Conselhos e Conferências de Saúde.

Formulação de política: intransferível, respeitando os princípios federativos e a área de responsabilidade do gestor.

Desenvolvimento das novas competências de gestão, sobre processos, produtos e serviços de interesse para a saúde, bem como sobre o meio ambiente (Constituição Federal, art. 200).

\section{As novas estruturas organizacionais}

Como foi dito, as novas funções de gestão, relacionadas a práticas de saúde tão diversificadas, acarretam grandes responsabilidades para o órgão de gestão do SUS, particularmente no nível local. Tais responsabilidades devem estar contidas em uma estrutura de gestão apropriada, bastante diferente daquela vigente nas etapas anteriores ao SUS, quando as competências de um órgão local de saúde eram muito menores.

No entanto, quando se fala em estrutura de gestão, o senso comum quase sempre busca a imagem de um organograma ou de um mero desenho esquemático de quadros e linhas, mostrando postos, funções, hierarquias, competências etc. O organograma, na verdade, deve ser considerado apenas uma consequência da estrutura, cuja definição e montagem ultrapassam, e muito, a idéia simplista do agrupamento de cargos e atribuições em um esquema lógico e hierarquizado. A estrutura é algo mais complexo e exige um conhecimento mais aprofundado da dinâmica da organização à qual se aplica. Aqui torna-se de grande valia o pensamento de Mintzberg, 
por meio do qual se poderá percorrer alguns caminhos para o entendimento de tal dinâmica e de sua adaptação às organizações públicas de saúde. A idéia é de que o percurso pelo referencial desse autor permitirá a compreensão e a proposição de estruturas adequadas às novas funções dos órgãos gestores de saúde.

Em primeiro lugar, é importante ressaltar que as organizações, quando se tornam mais complexas (e todas as organizações de saúde, desde o pequeno posto rural até os grandes órgãos gestores, podem ser consideradas complexas), passam a exigir dois mecanismos essenciais, embora conflitivos, para manter seu equilíbrio: a divisão de trabalho (entre pessoas e setores diferentes) e a coordenação das atividades daí decorrentes. A definição de uma estrutura organizacional, em termos ainda que singelos, deve resultar da soma dos meios empregados para dividir tarefas e realizar sua coordenação.

A coordenação, entretanto, representa uma atividade complexa e muitas vezes especializada. A complexidade das organizações humanas gerou a necessidade de mecanismos diversos para que a coordenação se realizasse. São eles: a) ajustamento mútuo, com a utilização de processos informais de comunicação; b) supervisão direta, ou responsabilização de uma pessoa pelo trabalho de outras; c) padronização de procedimentos, resultados e qualificação necessária para o trabalho.

$\mathrm{O}$ entendimento da dinâmica organizacional requer também que se realize algum aprofundamento sobre os circuitos ou fluxos que unem e articulam as diversas partes da organização, por meio dos quais circulam e produzem efeitos tais como os processos de decisão, os materiais e a informação. Mintzberg acentua que durante muitas décadas foram muito valorizados os fluxos de autoridade e de regulamentos, visão que aliás sustentou as escolas de pensamento administrativo mais antigas (taylorismo). Mas, não basta apenas o formalismo da autoridade e das regras para movimentar uma organização. O pensamento contemporâneo, para Mintzberg, contempla ainda os fluxos de comunicação informal, constelações de trabalho (organização do processo de trabalho a partir dos próprios indivíduos) e decisões ad hoc (aquelas tomadas no calor das circunstâncias, independentemente de estarem previstas nos regulamentos oficiais).

A dinâmica das organizações pode ser apreendida, ainda, a partir de suas partes componentes. Com efeito, a divisão de trabalho e os mecanismos de coordenação e padronização, desenvolvidos nas organizações complexas, passaram a exigir setores igualmente especializados e complexos, capazes de dar conta da diversidade de tarefas, sejam as operacionais (finalísticas) ou as administrativas (intermediárias). Nessa perspectiva, podem ser descritas cinco partes componentes da organização, que são: o Centro Estratégico (CE); a Linha Hierárquica (LH); o Centro Operacional (CO); o setor de Apoio Logístico (AL); e a Tecnoestrutura (TE). 
Seria um exercício produtivo tentar localizar cada uma das partes componentes de uma organização em um órgão gestor típico do sistema de saúde brasileiro.

O Centro Estratégico (CE) é de fácil visualização, pois corresponde ao locus organizacional onde se inserem o dirigente e sua estrutura de apoio. Aqui se realiza a formulação das estratégias de ação do órgão, baseadas na vontade, no poder e na política. Tais fatores podem derivar, por exemplo, dos programas de governo, da vontade de atender a determinados setores sociais, das demandas sociais encaminhadas pelo Conselho ou pela Câmara de Vereadores etc. No caso do SUS, o CE tem por responsabilidade realizar a articulação formal com o Conselho de Saúde, como organismo contíguo ao ambiente social, e captar e canalizar suas demandas, incorporando-as ou não, na formulação política e estratégica do órgão gestor. O Conselho de Saúde, portanto, é vinculado à estrutura do CE. A própria definição de gestor do SUS, nos termos colocados pela NOB/SUS/96, enfatiza o caráter de comando, de articulação com a sociedade e de formulação político-estratégica, que são inerentes a um CE.

O Centro Operacional (CO) é a parte essencial da organização de saúde, o lugar onde os operadores (na terminologia mintzbergiana) atuam. Nele decorrem os fatos, ou seja, são realizadas consultas, internações, visitas domiciliares, vacinações, auditorias hospitalares, fiscalização de estabelecimentos etc. O CO está representado pela rede de serviços de saúde, constituída pelos hospitais, centros e postos, clínicas, laboratórios, unidades móveis, setores de vigilância, além de outros. No CO, os operadores são: os enfermeiros, médicos, assistentes sociais, dentistas, auxiliares, técnicos e tantos outros profissionais, detentores da proficiência que caracteriza o coletivo de pessoas a realizar a função precípua da organização.

Mas, não basta ser um profissional de saúde para ser membro de um CO. Aliás, é bem comum o fato de se ter médicos, enfermeiros e outros profissionais no $\mathrm{CE}$ e nas outras partes da organização de saúde. Dado seu amplo contato com o ambiente social, o CO é extremamente vulnerável às demandas e mudanças ocorridas neste. Em caso de greve, por exemplo, é a paralisação do CO que afeta e contamina mais a dinâmica da organização. Por outro lado, esse é o setor que trabalha de forma mais protegida dentro da organização, proteção esta garantida por uma forte padronização de processos, resultados e qualificação. O CO tem ainda um peso político considerável dentro da organização, graças ao poder de seus membros (dado pela já referida proficiência), todos dotados de formação técnica (médicos, enfermeiros, dentistas e outros) cuja substituição é difícil, se não impossível a curto prazo. É bom ainda lembrar que, no SUS, uma parte dos cuidados à saúde pode não ser prestada diretamente pelo Poder Público, cabendo a este, em tal caso, o controle e a regulamentação 
dos prestadores. Tais atividades também pertencem ao $\mathrm{CO}$, ou a uma parte específica dele, dotada de competência técnica e política para atuar no controle e na auditoria dos prestadores de serviços contratados.

O CE e o CO estão interligados por meio da Linha Hierárquica (LH). Na verdade, esse é um componente extremamente variável nas organizações. Pode-se compreendê-lo por meio de uma imagem simples: quanto mais próximo o CE estiver do CO, menor será a LH. Em outras palavras, nas organizações pequenas, mas também naquelas realmente descentralizadas, a LH tende a desaparecer. Na situação tradicional do sistema de saúde, o que se tem é uma polaridade entre os órgãos de gestão e a rede de unidades, essas dotadas de pouca ou nenhuma autonomia. Nesse caso, estabelece-se uma LH, relativamente desenvolvida, com inumeráveis supervisores, coordenadores de programas, gerentes de áreas, chefes etc. Em um sistema de saúde realmente descentralizado, certamente a LH não desaparecerá, mas com toda certeza tenderá a ser mais curta e mais enxuta, já que muitas decisões dependentes de tais gerentes intermediários passarão a acontecer no $\mathrm{CO}$, ou seja, nas próprias unidades operacionais do sistema.

Os três componentes vistos acima, ou seja, CE, CO e LH possuem uma característica em comum: a de estarem articulados em função da missão e dos objetivos finais da organização, no caso, produzir ações e serviços de saúde. Contudo, em uma organização nem todas as suas partes têm esta característica de se inserir na produção direta do serviço ou bem para o qual a organização existe. Trata-se do caso dos dois componentes seguintes.

A Tecnoestrutura (TE) é o núcleo de análise, padronização e planejamento da organização. Nem sempre, porém, pode ser vislumbrado como tal. Aliás, até pelo contrário, pois muitas vezes o que se chama setor de planejamento em um órgão gestor não corresponde, de fato, às atribuições citadas, em princípio convergentes para a formulação estratégica da organização, mas sim ao cumprimento de uma série de rituais, como preenchimento (ou criação) de formulários, respostas às demandas de outros setores ou, simplesmente, contabilidade de eventos financeiros ou assistenciais. As funções de TE em saúde devem ser vislumbradas de maneira mais nobre e entre as mesmas podem ser citadas as seguintes: a) processamento da informação epidemiológica e gerencial; b) análise de conjunturas sanitárias e políticas, com vistas à antecipação das ações; c) definição de padrões referentes a procedimentos, resultados e qualificação de pessoal; d) proposição e execução de ações visando o alcance dos padrões definidos etc.

É fácil constatar que existe uma enorme diferença entre uma TE moderna e dotada de papel estratégico e aqueles setores burocratizados de planejamento que ainda proliferam no mundo das organizações de saúde. 
Pode-se dizer que não é necessária a presença física de um setor de TE nas organizações gestoras do SUS. O importante é que os referidos componentes nobres da mesma sejam contemplados nas funções de gestão e isso pode estar associado ao que se entende como $\mathrm{CE}$, no próprio $\mathrm{CO}$ ou, eventualmente, mesmo na LH.

O Apoio Logístico (AL), também afastado da linha direta de produção, é de uma visualização mais fácil em uma organização de saúde. Corresponde ao(s) setor(es) que se responsabiliza(m) por uma série de atribuições, ditas de suporte: orçamento, finanças, limpeza, transporte, vigilância, alimentação, treinamento, assessoria jurídica, administração do pessoal, comunicação, além de outras. Em muitos órgãos gestores o AL concentra-se na administração central, existindo nas secretarias e unidades de saúde apenas como postos avançados, do tipo controle de ponto, almoxarifados etc. Em outros, a própria secretaria mantém e estende seu $\mathrm{AL}$ à rede de unidades. Em cada unidade, todavia, o AL será sempre residual, fazendo parte e subordinando-se ao conjunto maior, representado pela secretaria ou pela administração municipal.

Finalizando o estudo da estrutura de gestão, vale a pena reforçar o que Mintzberg chama de configurações organizacionais, que se tratam de cinco variedades de configurações, definidas a partir dos conceitos vistos nas linhas acima. Destas, duas representam situações mais afins aos órgãos de saúde:

\section{Burocracia profissional}

Coordenação de trabalho realizada mediante padronização extensiva dos processos de trabalho e de qualificação. O Centro Operacional (CO) é a parte chave. Alta influência da força de proficiência das equipes de operadores. Dependência do trabalho de pessoas especializadas (burocracias). O CE articula-se com o ambiente social e resolve conflitos. A TE é pouco poderosa, equanto as funções de AL são muito elaboradas. Os fluxos de autoridade formal tendem a ser fracos. É a organização típica dos ambientes complexos, porém estáveis. As organizações de saúde tradicionais pertencem, geralmente, a essa configuração.

\section{Ad hocracia}

O mecanismo principal de coordenação é o ajustamento mútuo. A parte chave da organização está no AL ou no CO. Também dependente do trabalho de técnicos especializados, muito poderosos neste tipo de organização. O CE realiza o equilíbrio organizacional por meio da solução de conflitos e contatos com o exterior. A TE também é de pouca importância, ficando como que diluída no corpo organizacional. O AL deve ser bem estruturado. Fluxos de autoridade formal pouco significativos, de modo geral. Situação adequada para as organizações que atuam em ambientes complexos e muito mutáveis. 
Das estruturas definidas acima, não se pode dizer que uma está mais correta do que a outra. Ambas podem ser justificadas, de acordo com o tipo de organização e sua inserção no sistema de saúde. Assim, por exemplo, os órgãos gestores e até mesmo as unidades hospitalares, particularmente os de maior porte e complexidade, tendem a ser burocracias profissionais (ou até mecanicistas, ou seja, extremamente reguladas e programadas pela TE, segundo a mesma classificação de Mintzberg). Para unidades e programas que atuam na ponta da linha, em ambientes muito instáveis, a configuração adequada deve tender à ad hocracia.

Portanto, mais que pensar em reforma administrativa ou num novo organograma para organizações de saúde, é importante entender que tipo de organização pode ser capaz de assumir as funções de saúde, de acordo com os princípios aqui sistematizados. A grande exigência é de um novo tipo de organização, com maior flexibilidade, autonomia de trabalho, descentralização e gestão democrática. É o que se verá a seguir.

\section{A necessária flexibilidade}

O que caracteriza, de fato, uma organização flexível? Esse tipo de organização caracteriza-se pela flexibilidade em relação à definição de tarefas, que são distribuídas entre seus membros, a partir da definição do próprio grupo, com espaços para o exercício da criatividade. O trabalho é realizado a partir de projetos, com metas, prazos e recursos bem definidos, reunindo saberes e pessoas de áreas e especialidades diferentes, sob o comando de um gerente designado especificamente para a atividade em questão. As decisões ad hoc são freqüentes e muito valorizadas.

Organizações flexíveis permitem mudanças nas formas como se organiza tradicionalmente o processo de trabalho em saúde, com especialização e verticalização da divisão entre corpo clínico, de odontologia, enfermagem, e outros. Ao mesmo tempo, permite a responsabilização das equipes pelos problemas a serem enfrentados pelo serviço de saúde e pela definição dos mecanismos capazes de resolvê-los (Giacomini, 1994).

Essas novas estruturas, típicas da ad hocracia, por meio da autofixação de metas e do estímulo ao trabalho a partir de condições autônomas, são capazes de produzir inovação, ao estimular a criatividade individual e coletiva, e incorporar idéias novas com repercussões no processo de mudança organizacional.

É bastante comum a configuração flexível ser representada por uma estrutura modular, baseada em equipes organizadas sob a forma de matrizes ou estruturas matriciais, para usar um termo mais em evidência (Medici \& Silva, 1993). 
Para completar a presente discussão, a questão que cabe formular, a partir do quadro de referência dado por Mintzberg, é a seguinte: como incorporar, na organização tradicional burocrática, componentes operacionais da modalidade ad hocrática mais flexível e adequada ao ambiente de mutabilidade e incerteza que caracteriza a prestação de serviços de saúde?

São muitas as possibilidades, mas os aspectos mais fundamentais de tal mudança podem assim ser descritos:

- transferência do poder decisório para os setores mais operacionais, ou seja, a contrapartida local da descentralização que, no caso do SUS, se propõe;

- não separação das atividades de fazer daquelas de pensar, ou seja, a TE de planejamento e análise devidamente diluída e incorporada nos diversos setores da organização;

- estímulo e reforço às decisões ad hoc e ao comportamento criativo, de maneira geral;

- estímulo aos processos de trabalho desenvolvidos espontaneamente na organização, a partir das capacidades e dos desejos individuais — as constelações de trabalho (Mintzberg) — sem que isso signifique, necessariamente, abrir mão dos objetivos institucionais;

- clareza a respeito da missão organizacional (produzir saúde), de forma a impedir que os meios (produzir normas) se tornem mais importantes que os fins;

- desenvolvimento de atividades em estruturas matriciais, que se tratam na verdade de arranjos ad hoc, para resolver problemas específicos. Exemplo: uma equipe de atenção ao adolescente formada por enfermeira, pediatra, psicólogo e assistente social de setores diferentes (no organograma), porém voltados para um programa específico: dar atenção a esse tipo de clientela. 


\section{Referências bibliográficas}

Dussault, G.. (1992), "A gestão dos serviços públicos de saúde: características e exigências”. Revista de Administração Pública, abril/junho, n. 26 (2):8-19. Rio de Janeiro.

Giacominı, C. H.. (1994), Descentralização e Distritos Sanitários: aproximação ao deslocamento de poder no processo de distritalização da Secretaria Municipal de Saúde de Curitiba. Dissertação de mestrado. Londrina, Universidade Estadual de Londrina.

Lima, S. M. L. e Barbosa P.R.. (1998), "Planejamento e Gestão em Saúde (I): aspectos conceituais e abordagens contemporâneas”. Curso de Educação à Distância em Gestão de Saúde. Rio de Janeiro. FIOCRUZ/UnB.

MÉDICI, A. C. e SILVA, P. L. B.. (1993), "Administração flexível: uma introdução às novas filosofias de gestão". Revista de Administração Pública, 26, julho/setembro. Rio de Janeiro.

MintZberg, H.. (1995), Criando Organizações eficazes. São Paulo: Atlas.

Mintzberg, H.. (1982), Structure et dynamique des organisations. Paris: Les Éditions d'Organisations.

Müller, J.. (1993), "O papel estratégico do dirigente municipal de saúde". Curso para Dirigentes Municipais de Saúde, Rio de Janeiro, IBAM/FNS. 


\section{Da burocracia à ad hocracia}

Flavio A. de Andrade Goulart e Rosani Evangelista da Cunha

As organizações de saúde são sempre organizações complexas, que realizam seus objetivos por intermédio das funções de gestão, nome que se dá ao conjunto de atributos de gestão e de gerência relacionados ao âmbito dos sistemas e dos serviços de saúde, seja no plano político, técnico-finalístico ou técnico-administrativo.

Funções de gestão e práticas de saúde devem estar contempladas em uma estrutura de gestão. A estrutura é algo mais complexo do que um simples organograma. O entendimento da dinâmica organizacional e de sua adaptação às organizações concretas, segundo o referencial do autor canadense, H. Mintzberg, é fundamental para se propor estruturas adequadas às novas funções dos órgãos gestores em saúde.

A grande exigência para a organização de saúde contemporânea é a de maior flexibilidade, com autonomia de trabalho, descentralização e gestão democrática. O processo de trabalho deve apoiar-se em projetos, com metas, prazos e recursos bem definidos, reunindo saberes e pessoas de áreas e especialidades diferentes, sob mandatos que podem não ser permanentes, mas designados especificamente para as necessidades.

\section{De la burocracia a la ad hocracia}

\section{Flavio A. de Andrade Goulart y Rosani Evangelista da Cunha}

Las organizaciones de salud son siempre organizaciones complejas. Además, estas organizaciones realizam sus objectivos por intermedio de las funciones de gestión, es decir, el conjunto de atributos de gerencia ubicados en el ámbito de los sistemas y servicios de salud, tanto en los planos político, administractivo o técnico-finalístico.

Las funciones de gestión y las prácticas de salud debem estar contenidas en la estructura organizacional, que es algo más complejo que un simple organigrama. El marco referencial propuesto por el autor canadiense H. Mintzberg es muy útil para la compreensión y la proposición de las estrucuturas más adecuadas para las nuevas funciones de gestión en salud.

La complejidade creciente del trabajo, de la coordinación y estandartización desarolladas en las organizaciones de salud, ha pasado a exigir sectores y personas cada vez más especializados, capaces de cumplir las tareas operacionales. El proceso de trabajo debe basarse en proyectos, con metas, plazos y recursos bien definidos, reuniéndose personas y conocimientos diferentes, con mandatos que puedem no ser permanentes, sino designados especificamente hacia cada tipo de actividad, en función de las necesidades.

\section{From bureaucracy to ad hocracia}

\section{Flavio A. de Andrade Goulart and Rosani Evangelista da Cunha}

Health organizations are always complex entities. This kind of organization reach its objectives by means of the manager functions, which are a bunch of attributes related to health systems and services, in terms of politics, technical approach and managing.

Health functions and health practices should be included in a managerial structure, that is more complex than a single organograme. The theoretical contributions of a Canadian author, H. Mintzberg, may be important for the comprehension and even the formulation of adequated strucutures for the health managing organizations.
Revista do

Serviço

Público

Ano 50

Número 3

Jul-Set 1999

Flavio A.

de Andrade

Goulart,

docente da

Faculdade de

Ciências da

Saúde/UnB e

doutorando em

Saúde Pública

na ENSP/

FIOCRUZ,

Rio de Janeiro.

Rosani

Evangelista

da Cunha, mestranda em

Administração

na FACE/UFMG

e assessora

técnica da

Frente Nacional de Prefeitos 
The increasing complexity of the division of labor and of coordination and standartization mechanisms in the modern health organizations created the necessity of more and more specialized people and instruments. The work process should be supported by projects, with well established goals, timing and resources, which join together people and expertise from different professional areas, with not necessarily permanent mandates and direction, although oriented specifically for each kind of needs and activities. 